\title{
The Spectral Measurement of Scattered Radiation From a Clinical Linear Accelerator Using a CZT Detector
}

\author{
Fouad A. Abolaban ${ }^{1} \quad$ Yazeed F. Alshehri $^{1} \quad$ Basil A. Khayat $^{1} \quad$ Turki M. Bafail $^{1} \quad$ Saeed S. Alsebaeai $^{1}$ \\ Abdulsalam M. Alhawsawi ${ }^{1,2} \quad$ Mawya Khafaji $^{3} \quad$ Khalid Alsafi $^{3} \quad$ Ahmad Hussain $^{4}$ \\ 1.King Abdulaziz University, Faculty of Engineering, Nuclear Engineering Department, P.O. Box 80204, Jeddah \\ 21589, Saudi Arabia \\ 2.King Abdulaziz University, Center for Training \& Radiation Prevention, P.O. Box 80204, Jeddah 21589, Saudi \\ Arabia \\ 3.King Abdulaziz University, School of Medicine, Department of Radiology, P.O. Box 80204, Jeddah 21589, \\ Saudi Arabia \\ 4.DHA Suffa University, Department of Mechanical Engineering, Karachi, Pakistan
}

\begin{abstract}
The study of the induced radioactivity following radiotherapy with high energy X-rays from medical linear accelerator. Patient equivalent phantom made of Polymethyl methacrylate (PMMA) of 30x30x27 cm size irradiated with 15 MV X-rays from Versa HD medical linear accelerator form Elekta. Induced radioactive and ambient dose rates were measured at $0.25,0.5$ and $1 \mathrm{~m}$ from beam center using GR1® spectrometry with Cadmium Zinc Telluride (CZT) detectors having energy resolution less than $2 \%$. Spectrum analysis was performed using MultiSpect software. The measured spectrum showed $511 \mathrm{keV}$ annihilation photons possibly as a result of positron emitter of which most likely candidates are ${ }^{62} \mathrm{Cu}(\mathrm{T} 1 / 2: 9.7 \mathrm{~min}),{ }^{64} \mathrm{Cu}(\mathrm{T} 1 / 2: 12.7 \mathrm{~h})$ and ${ }^{57} \mathrm{Ni}(\mathrm{T} 1 / 2: 35.6 \mathrm{~h})$ and a peak at $\approx 1780 \mathrm{keV}$ that could be attributed ${ }^{28} \mathrm{Al}$ and ${ }^{214} \mathrm{Bi}$ radioisotope. Ambient photon dose rates post radiotherapy treatment ranged $660 \mu \mathrm{Gyh}^{-1}$ at $0.5 \mathrm{~m}$ to $41 \mu \mathrm{Gyh}^{-1}$ at $1 \mathrm{~m}$. These values agree well with the results presented in the literature.
\end{abstract}

Keywords: Radiotherapy; Activation Products; Gamma spectrometry; Occupational exposure; Medical Linear Accelerator.

DOI: $10.7176 /$ ALST/83-05

Publication date: November $30^{\text {th }} 2020$

\section{Introduction}

Medical linear accelerators (LINAC) are among the most important modalities for cancer treatment in modern healthcare [1,2]. Even though there are several options available for cancer treatment, LINAC is the most commonly used due to their advantages of low skin dose and high depth dose for killing cancer cells further reducing scattered radiation that could be exposed to healthy tissues outside the tissue-target volume $[3,4]$. As a result, about $90 \%$ of radiation therapy treatment are carried out using electrons and high energy photon from medical linear accelerators.

During LINAC operation, undesired photoneutrons are created from the interactions of the incident high energy photons with materials in the accelerator head such as targets, flattening filters and collimation systems and other structural materials [1]. These neutrons are formed when the incident photon energy fall above $8 \mathrm{MeV}$, the threshold energy for the $(\gamma, n)$ photonuclear reaction mainly due to the giant dipole resonance reactions. Other unimportant reactions are photodisintegrations $(\gamma, 2 \mathrm{n}),(\gamma, \mathrm{p})$.

Photoneutrons are produced as a result of interaction of high energy photons with materials in the radiotherapy linear accelerator head including $\mathrm{W}, \mathrm{Pb}, \mathrm{Cu}$ and $\mathrm{Fe}$. In particular, the high atomic number materials in the linac head: tungsten and lead have very low absorption cross sections for the photoneutrons produced and thus does not affect the intensity of the produced photoneutrons [5]. Photoneutrons produced in medical linear accelerator could undergo $(\mathrm{n}, \gamma)$ neutron capture reaction inducing different activation products. Accordingly, the radiotherapy treatment room is contaminated with radioactive products mostly exist inside the primary beam with half-lives that range from 5 minute to 5 years subsequently exposing the patients and radiation therapy technologists to unnecessary excessive radiation doses. As a result, activation products inside the treatment room post radiotherapy remain the most significant source of occupational exposure to radiotherapy technologist, who repeatedly enter the treatment room following radiotherapy to manage patient or physicists involved in quality control and dosimetric measurements whose work demand repeatedly entrance in the treatment room post radiotherapy

Several studies have been performed in the literature to study to study both $(\gamma, n)$ and $(n, \gamma)$ reaction flowing radiotherapy with high energy X-rays and their associated occupational dose and radiation risk to nearby individuals. Petrovic et al. (2011) measured radioactive isotopes following radiotherapy with X-rays and have identified ${ }^{28} \mathrm{Al}$ and ${ }^{62} \mathrm{Cu}$ short half-life but also ${ }^{56} \mathrm{Mn},{ }^{64} \mathrm{Cu}$ and ${ }^{187} \mathrm{~W}$ of medium half-life [6]. In a similar study, spectrometric measurements were made in a treatment room following a radiotherapy with 18 MV X-rays. 
Radioisotopes produced as a result of photoneutron capture in the linear accelerator head included: ${ }^{187} \mathrm{~W},{ }^{63} \mathrm{Zn}$, ${ }^{56} \mathrm{Mn},{ }^{24} \mathrm{Na}$, and ${ }^{28} \mathrm{Al}$. The authors have also estimated an occupational exposure level of $750 \mathrm{mSv} \cdot \mathrm{y}^{-1}$ at the patient site. They concluded that closing the linac jaws before re-entering the treatment room could reduce annual exposure at the patient site to $65 \mathrm{mSv}$ [7]. M. Janiszewskal et al. (2013) have measured the unwanted excessive dose following the radiotherapy using $18 \mathrm{MV}$ high energy X-rays from using a medical linear accelerator [8]. The main source of the excessive dose was attributed to radioscopes Mn56 in the stainless steel and W187 from the collimation materials in addition to positron emitters from $[\mathrm{n}, \gamma]$ activation reaction. Neutron contamination following radiotherapy with high energy X-rays has been an important area of research interest in terms of induced nuclear reactions, secondary cancers to radiotherapy patients and unwanted excessive dose that contribute to the occupational exposure of the radiotherapy technologist.

Herein we aimed to investigate the activation products and the quantity of uncalculated dose in treatment room following radiotherapy with Megavoltage X-rays. The study results will be used to enhance radiation protection of patient and workers involved in radiotherapy.

\section{Materials and Methods}

The experimental measurements were performed on a linear accelerator type Versa HD form Elekta located at Radiotherapy Unit of the King Abdelaziz University hospital in Jeddah, Saudi Arabia.

The study was aimed to measure the activation products and the quantity of uncalculated dose in treatment room following radiotherapy with Megavoltage X-rays. As both short-lived and long-lived radionuclides are generated, measurements were made before treatment to measure long-lived radionuclides produced from previous treatments and immediately after ceasing the treatment to measure the short-lived radionuclides. Thus, the study is focused on two areas of interest noted as 1 and 2 in Figure 1, which is time before starting-up the machine and after closing down the machine.

\section{(Figure 1)}

To simulate typical radiation scatter conditions, patient equivalent phantom made of 12 slabs of PMMA with $30 \times 30 \times 2.25 \mathrm{~cm}$ each for a total height of $27 \mathrm{~cm}$ were placed on the couch at the center of the $20 \times 20 \times 20 \mathrm{~cm}$ field size aligning the beam iso-center to slabs center (Figure 2). The experimental setup was irradiated with 15 MV X-rays at source-to-surface distance of $0.95 \mathrm{~m}$.

Radioactive products were measured using Quant for GR1® spectrometry with Cadmium Zinc Telluride (CZT) detectors having energy resolution less than 2\% and equipped with MultiSpect software. Energy and efficiency calibration of Quant for GR1@ spectrometry was carried out using $662 \mathrm{keV}$ for $\mathrm{Cs}^{137}$ and 1173 \& $1332 \mathrm{keV}$ for $\mathrm{Co}^{60}$ standard sources. Radioactivity was measured using CZT detectors was placed on the couch successively at three different positions from the center of the slabs at distances of $25 \mathrm{~cm}, 50 \mathrm{~cm}$ and $100 \mathrm{~cm}$ from the center of the beam (Figure 3).

(Figure 2)

(Figure 2)

Moreover, CZT detector was connected to a laptop by a long cable to avoid damaging the laptop electronics. MultiSpect software was used to start the experiment and the time of each measurement did not exceed 5 minutes, taking the measurement twice for each position to see if there is difference between each trial. The time gap between each trial is estimated to be 4-5 minutes to change the setup and preparing the timers. Figure 1 shows PMMA labs placed over the couch to simulate patient scatter.

Radiations absorbed dose in the CZT detector using the obtained count rate using the following relation [9]:

$$
\dot{\mathrm{D}}=\frac{\emptyset\left[\frac{\text { photon }}{\mathrm{m}^{2} \cdot \mathrm{s}}\right] \cdot \mathrm{E}\left[\frac{\mathrm{MeV}}{\text { Photon }}\right] \cdot \mu_{\mathrm{m}}\left[\mathrm{m}^{-1}\right] \cdot 1.6 \times 10^{-18}\left[\frac{\mathrm{J}}{\mathrm{MeV}}\right] \cdot 3.6 \times 10^{8}\left[\frac{\mathrm{s}}{\mathrm{hr}}\right]}{\rho\left[\frac{\mathrm{kg}}{\mathrm{m}^{8}}\right] \cdot 1\left[\frac{\mathrm{Kg}}{\mathrm{Gr}}\right]}
$$

Were: $\emptyset=$ photon flux; $E=$ energy of photon, $\mu_{\mathrm{m}}=$ mass absorption coefficient of CZT detector crystal and $\mathbf{P}=$ density of CZT crystal.

The activity of the induced radioisotopes is defined as particle per second and is taken the same as the photon flux in dose calculation using equation 1 . Mass absorption coefficient of CZT crystal $\left(\mu_{\mathrm{m}}\right)$ are taken from the published literature [10].

\section{Results}

Spectrometric measurements are presented for the radioactivity inside radiotherapy treatment room at measurements points located at $0.25 \mathrm{~m}, 0.5 \mathrm{~m}$ and $1.0 \mathrm{~m}$ distances from the beam center.

Figure 4 Shows the spectrum of the radioactivity measurements in the treatment room using, CZT detector showing the areas of interest identified with color to show different spectrum zones. Because of very large ratio 
of counts rates, these three zones were defined to help understand the graph easier with the exception of peaks being present. Figure 5 Shows the spectrum of the radioactivity measurements in the treatment room showing photopeak locations. Five peaks were

Identified possibly coming from radioactive products or scatted radiation coming from the treatment head.

(Figure 4)

(Figure 5)

Table 1 shows (n, $\gamma$ ) activation products in the treatment room measured using CZT detector. Only peaks 4 $\& 5$ are the possible source of radioactive isotopes as a result $(\mathrm{n}, \gamma)$ reactions. Peak 4 shows $511 \mathrm{keV}$ annihilation photons possibly as a result of positron emitter isotopes of which most likely candidates are ${ }^{62} \mathrm{Cu}(\mathrm{T} 1 / 2: 9.7 \mathrm{~min})$, ${ }^{64} \mathrm{Cu}(\mathrm{T} 1 / 2: 12.7 \mathrm{~h})$ and ${ }^{57} \mathrm{Ni}(\mathrm{T} 1 / 2: 35.6 \mathrm{~h})$. Peak $5 \approx 1780 \mathrm{keV}$ and could be traced back to be ${ }^{28} \mathrm{Al}$ and ${ }^{214} \mathrm{Bi}$ radioisotope that are mostly likely to be generated via $(n, \gamma)$ interactions inside treatment room.

(Table 1)

Table 2 shows the ambient dose rates inside radiotherapy treatment room measured using CZT detector. Dose rates were measured at $0.25 \mathrm{~m}, 0.5 \mathrm{~m}$ and $1.0 \mathrm{~m}$ distances from the beam center resulting $2.590,0.660$ and $0.041 \mathrm{mGyh}^{-1}$, respectively. The spectrum showing dose rates are graphically depicted in Figures 6 to 8 .

(Table 2)

(Fig. 7)

(Fig. 8)

\section{Discussion}

Most neutrons produced following radiotherapy with medical linear accelerator are coming from $(\gamma, \mathrm{n})$ reactions whose cross section is high for high $\mathrm{Z}$ materials such as tungsten and lead. Other materials such as iron or aluminum can also produce photoneutrons, but their low cross section requires a high photon flux for a significant contribution of photoneutrons. Activation product as a results $(n, \gamma)$ neutron capture interaction disintegrate by emitting $\gamma$-rays, $\beta+$ and $\beta$ - particles with half-lives that range from 2 min to more than 5 years $[7,11,12]$. Thus, deemed as the major source of occupational radiation exposure for technologist and physicist who repeatedly enter the treatment room after radiotherapy treatment for patient management or quality assurance measurements $[13,14]$.

Spectrometric measurements performed in this study showed an interesting result. As shown in Figure 1, the $511 \mathrm{keV}$ energy is due to annihilation photons due to $\beta+$ and $\beta$ - decays, which suggest the presence of activation products such as ${ }^{62} \mathrm{Cu},{ }^{64} \mathrm{Cu}$ and ${ }^{57} \mathrm{Ni}$. The $\approx 1850$ peak is traced back to be ${ }^{28} \mathrm{Al}$ and ${ }^{214} \mathrm{Bi}$ radioisotope that are mostly likely to be generated via photoneutron interactions inside treatment room. These results are in agreement with the results of study by Petrovic et al. (2011), who measured radioactive isotopes following radiotherapy with X-rays included ${ }^{28} \mathrm{Al}$ and ${ }^{62} \mathrm{Cu},{ }^{56} \mathrm{Mn},{ }^{64} \mathrm{Cu}$ and ${ }^{187} \mathrm{~W}$ [6]. Ateia et al. (2008) studied the activation products in radiotherapy linear accelerator identifying ${ }^{28} \mathrm{Al},{ }^{62} \mathrm{Cu},{ }^{56} \mathrm{Mn},{ }^{64} \mathrm{Cu},{ }^{187} \mathrm{~W}$, and ${ }^{57} \mathrm{Ni}$ as radioisotopes following radiotherapy treatment [7]. Some differences exist in the type of radionuclide detected as this is related to differences in materials in the accelerator head. The main concern of radioisotopes in the treatment room is it is contribution in the unwanted excessive dose to the technologist who enters the treatment room repeatedly after radiotherapy thus contributing to annual dose.

According to the International Commission on Radiological Protection (ICRP), occupational exposure of radiation workers is entailed to satisfy the principles of radiation limit, which is an annual effective dose of 20 $\mathrm{mSv}$ [15]. As shown in Table 3, the excessive unwanted dose rates out the treatment field was about $41 \mu \mathrm{Gyh}^{-1}$. Ateia et al. (2008) the measured dose rates at the isocenter ranged from $2.2 \mu \mathrm{Sv} / \mathrm{h}$ to $10 \mu \mathrm{Sv} / \mathrm{h}$ [7]. it was observed by the authors that within 10 minutes after ceasing the linear accelerator operation, the dose rate decreased to values of $0.8 \mu \mathrm{Sv} / \mathrm{h}$.

\section{Conclusion}

Spectrometric measurements have been carried out for the induced radioactivity as a results neutron capture reaction following radiotherapy with $15 \mathrm{MV}$ X-rays from medical linear accelerator. $511 \mathrm{keV}$ annihilation photons believed to come from $\beta+$ and $\beta$ - emitter as well as peaks at high energy gamma lines that are attributed to ${ }^{28} \mathrm{Al}$ and ${ }^{214} \mathrm{Bi}$ radioisotope as a result $(\gamma, \mathrm{n})$ and $(\mathrm{n}, \gamma)$ interaction in the linear accelerator treatment head. The results revealed a significant radiation risk to technologists entering the treatment room post radiotherapy that require urgent protection measures to mitigate the radiological risk of post neutron capture induced activation materials and to reduce the unnecessary excessive radiation dose to technologist. The results highlighted a clear room for continuing research in this area to further investigate dose levels due neutron contamination, the induced radioactivity post radiotherapy and levels of unwanted doses due to both $(\gamma, \mathrm{n})$ and $(\mathrm{n}, \gamma)$ reaction following radiotherapy with high energy X-rays. 


\section{References}

1. Yücel H, Çobanbaș İ, Kolbaşı A, Yüksel AÖ, Kaya V: Measurement of photo-neutron dose from an 18-MV medical linac using a foil activation method in view of radiation protection of patients. Nuclear Engineering and Technology 2016, 48(2):525-532.

2. Yücel H, Çobanbaș İ, Kolbașı A, Yüksel AÖ, Kaya V: Measurement of photo-neutron dose from an 18-MV medical linac using a foil activation method in view of radiation protection of patients. Nuclear Engineering and Technology 2016, 48(2):525-532.

3. Barquero R, Mendez R, Vega-Carrillo HR, Iñiguez MP, Edwards TM: Neutron spectra and dosimetric features around an $18 \mathrm{MV}$ linac accelerator. Health physics 2005, 88(1):48-58.

4. Howell RM, Ferenci MS, Hertel NE, Fullerton GD, Fox T, Davis LW: Measurements of secondary neutron dose from $15 \mathrm{MV}$ and $18 \mathrm{MV}$ IMRT. Radiation protection dosimetry 2005, 115(1-4):508-512.

5. Nourmohammadi B, Mesbahi A. A review on the radiation therapy technologist received dose from induced activation in high-energy medical linear accelerators. Radiation protection dosimetry. 2018 Jun $1 ; 179(4): 333-48$.

6. N. Petrovic, J. Krestic-Vesovic, D. Stojanovic, O. Ciraj-Bjelac, D. Lazarevic, and M. Kovacevic, "Contribution of activation products to occupational exposure following treatment using high-energy photons in radiotherapy," Radiat. Prot. Dosimetry, vol. 143, no. 1, pp. 109-112, Jan. 2011, doi: $10.1093 / \mathrm{rpd} / \mathrm{ncq} 290$.

7. E. Ateia, O. Ciraj-Bjelac, M. Kovacevic, P. Belicev, B. Cvetkovic, and I. Anicin, "Additional dose assessment from the activation of high-energy linear accelerators used in radiation therapy," Nucl. Technol. Radiat. Prot., vol. 23, no. 2, pp. 58-64, 2008, doi: 10.2298/NTRP0802058A.

8. M. Janiszewska, K. Polaczek-Grelik, M. Raczkowski, B. Szafron, A. Konefał, and W. Zipper, "Secondary radiation dose during high-energy total body irradiation," Strahlenther. Onkol., vol. 190, no. 5, pp. 459-466, May 2014, doi: 10.1007/s00066-014-0635-z.

9. T. E. Johnson and H. Cember, Introduction to health physics, Fifth edition. New York: McGraw-Hill Education, 2017.

10. Redus and Xr - Efficiency of Amptek XR-100T-CdTe and -CZT Detecto.pdf." Accessed: May 23, 2020. [Online]. Available: https://www.amptek.com/-/media/ametekamptek/documents/resources/cztapp1.pdf.

11. Fischer, H. W., Tabot, B. and Poppe, B. Comparison of activation products and induced dose rates in different high-energy medical linear accelerators. Health Phys. 94 (3), 272-278 (2008).

12. Wang, Y. Z., Evans, M. D. C. and Podgorsak, E. B. Characteristics of induced activity from medical linear accelerators. Med. Phys. 32(9), 2899-2910 (2005)

13. Keehan, S., Taylor, M. L., Smith, R. L., Dunn, L., Kron, T. and Franich, R. D. Dose and gamma-ray spectra from neutron-induced radioactivity in medical linear accelerators following high-energy total body irradiation. Radiat. Prot. Dosim. 172(4), 327-332 (2016).

14. Donadille, L. et al. Radiation protection of workers associated with secondary neutrons produced by medical linear accelerators. Radiat. Meas. 43(2-6), 939-943 (2008)

15. ICRP (International Commission on Radiological Protection), 2007. The 2007 Recommendations of the International Commission on Radiological Protection. ICRP Publication 103, Ann. ICRP 37, (Pergamon Press, Oxford, UK).

Table 1. (n, $\gamma$ ) activation products from medical linear accelerator

Spectrum Energy Analysis

Peak 1

Small peak of only 67 counts could be background a scattered radiation coming from main beam

Peak 2 \& 3

Peak $4 \quad 511 \mathrm{keV}$

The explanation is that they are simply scattered radiation from treatment rom

Peak $5 \approx 1780$

(Area 2) Annihilation photons as a result of positron emitter isotopes of which most likely candidates are ${ }^{62} \mathrm{Cu},{ }^{64} \mathrm{Cu}$ and ${ }^{57} \mathrm{Ni}$.

Area 2 shows a very unclear photopeak of energy due to short experiment time, the peak is traced back to be ${ }^{28} \mathrm{Al}$ and ${ }^{214} \mathrm{Bi}$ radioisotope that are mostly likely to be generated via photoneutron interactions inside treatment room. 
Table 2 Ambient dose rates from $(n, \gamma)$ activation product from medical linear accelerator

Position

(distance)

Position 1

$(25 \mathrm{~cm})$

Position 2

$(50 \mathrm{~cm})$

Position3 (100 0.041

$\mathrm{cm})$

2.590

0.660

\section{Dose rates Comments}

$\left(\mathrm{mGyh}^{-1}\right)$

Counts around $511 \mathrm{keV}$ appeared which might suggest that this region have a lot of annihilation interaction,

energies of 326 and $338 \mathrm{keV}$ scored high number of counts which might suggest of this region is main region of radioisotopes formulation.

only on low energies that ranges from 40-70 keV which might be the 'leftover' radiation that didn't interacted with matter traveling to this distance, those photons might be secondary or scattered radiation inside room.

\section{DOSE VS. TIME}

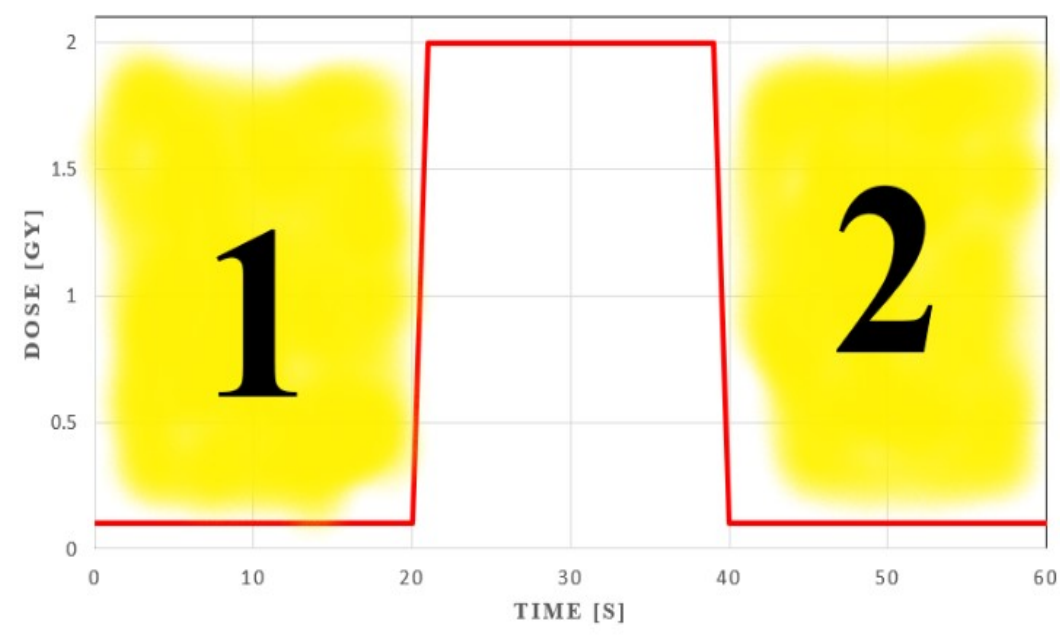

Figure 1 Dose and Time relationship in radiotherapy treatment room

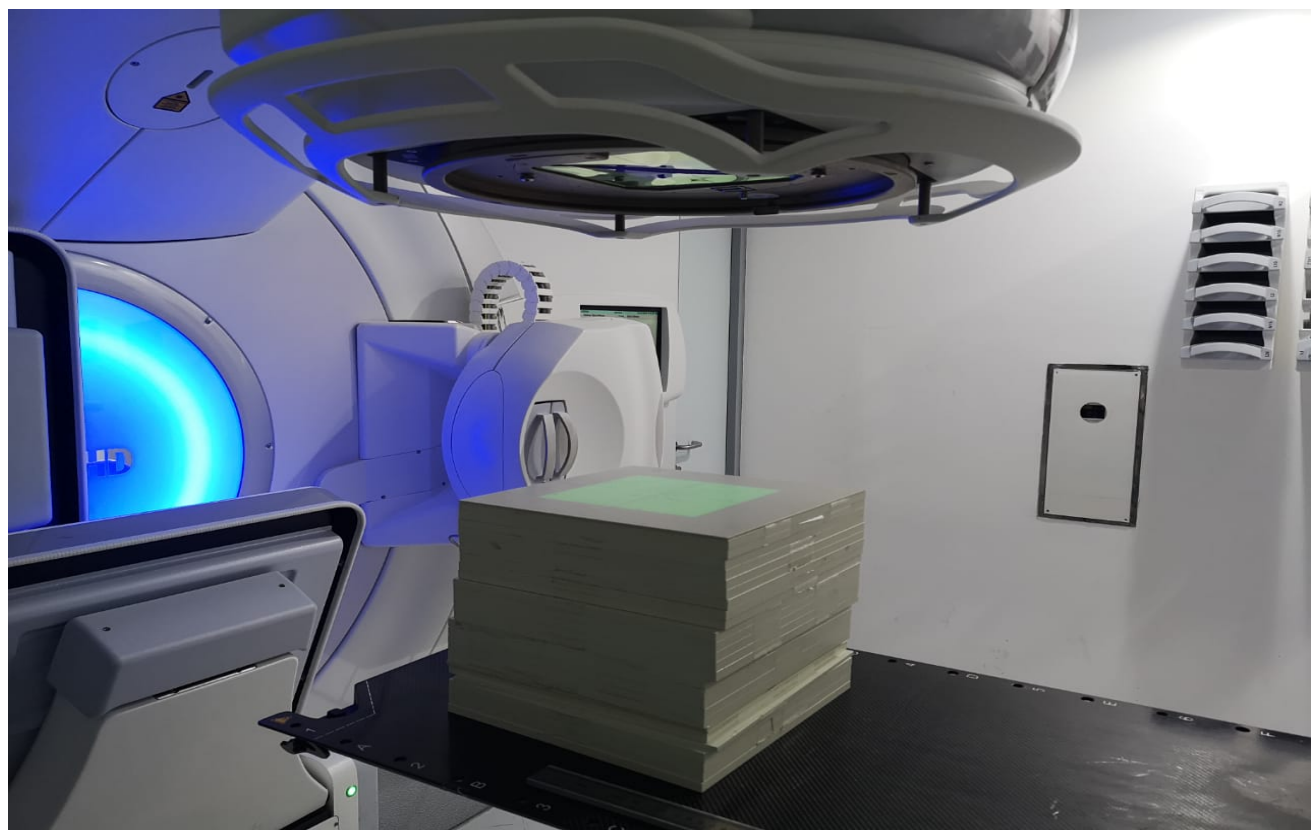

Figure 2 The PMMA slabs used in this experiment to simulate patient scatter 


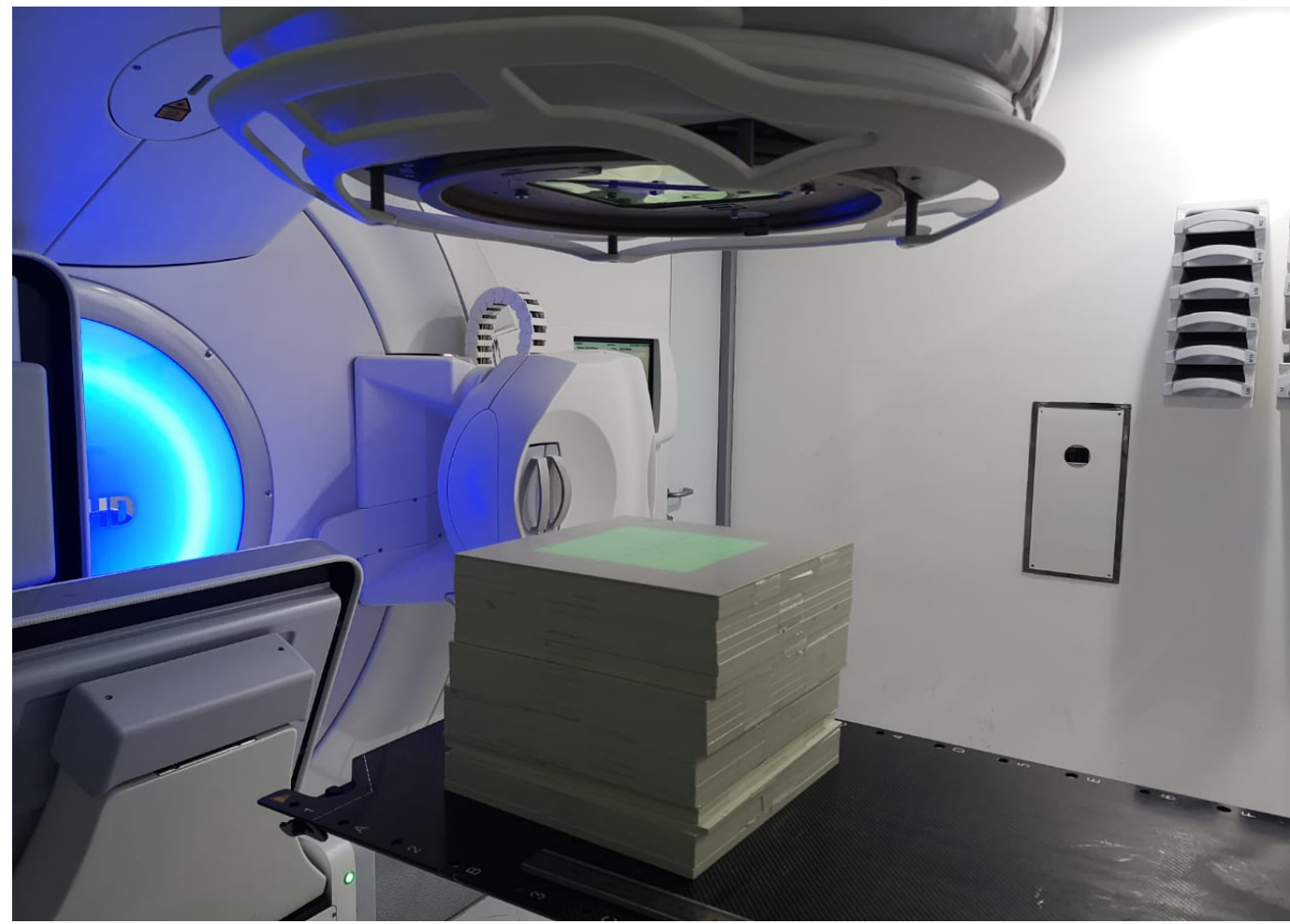

Figure 2 The slabs used in our experiment.

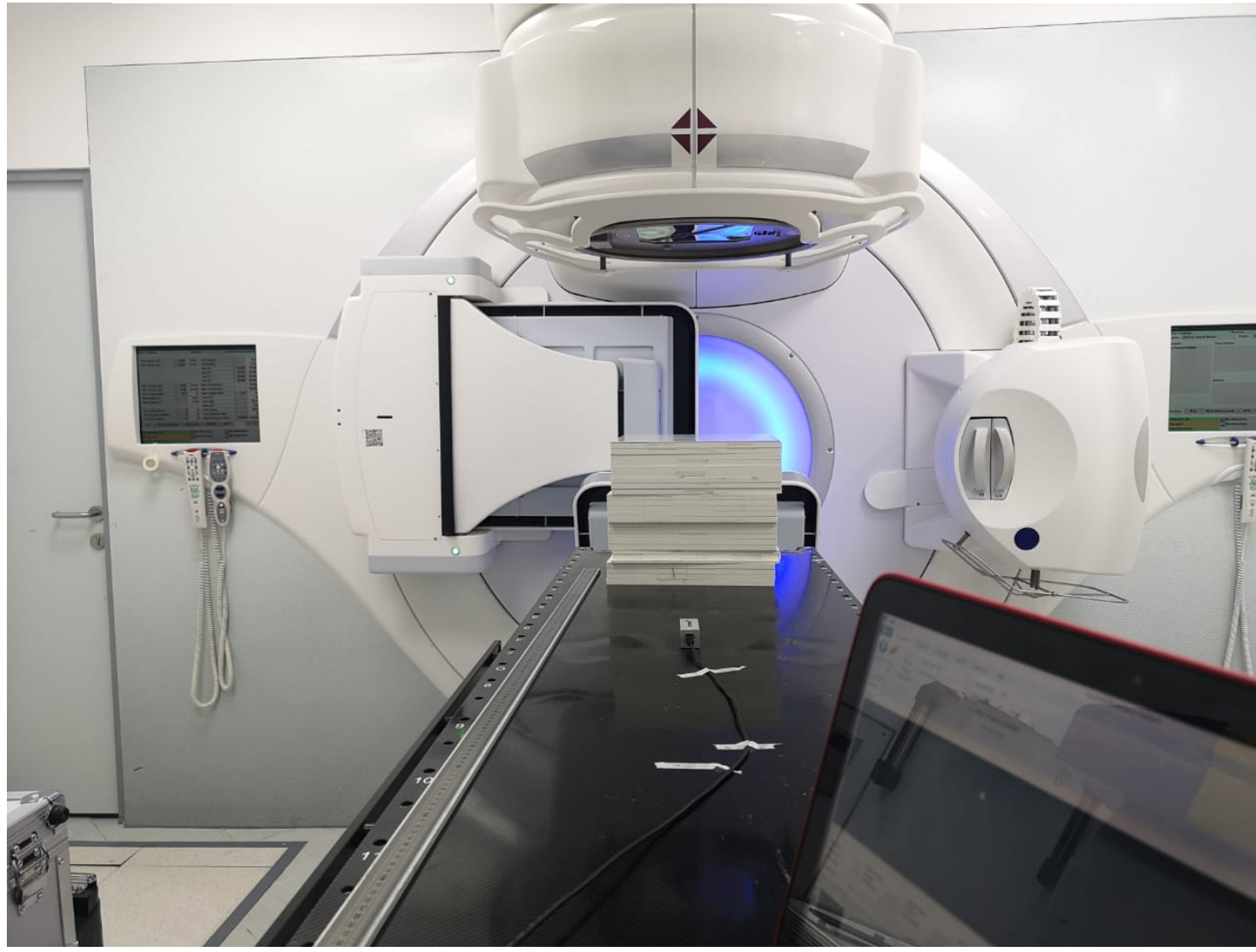

Figure 3 the experimental setup for measurements of radioactivity post radiotherapy with high energy X-rays 


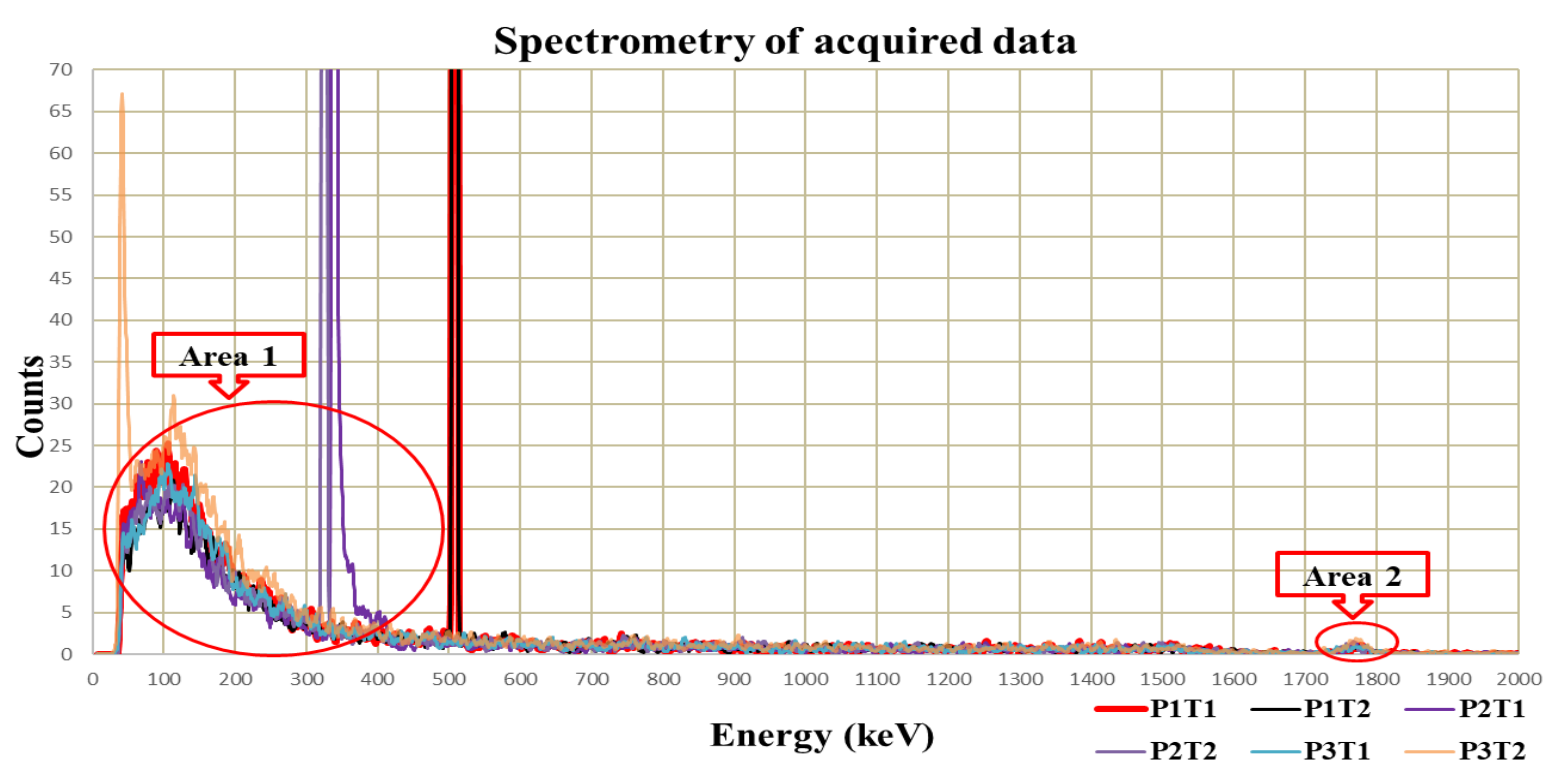

Figure 4 Shows the spectrum of the radioactivity measurements in the treatment room using, CZT detector showing the areas of interest identified with color to show different spectrum zones (Red, 0-0.5 MEV, > 10 counts; Yellow, 0.5-1.85 MEV, < 3 counts; Blue, 1.85-3.0 MeV, 1< count); (P1T1 \& P1T2, trial $1 \& 2$ position 1; P2T1 \& P2T2, trial 1\& 2 position 2; P3T1 \& P3T2, trial 1\& 2 position 3).

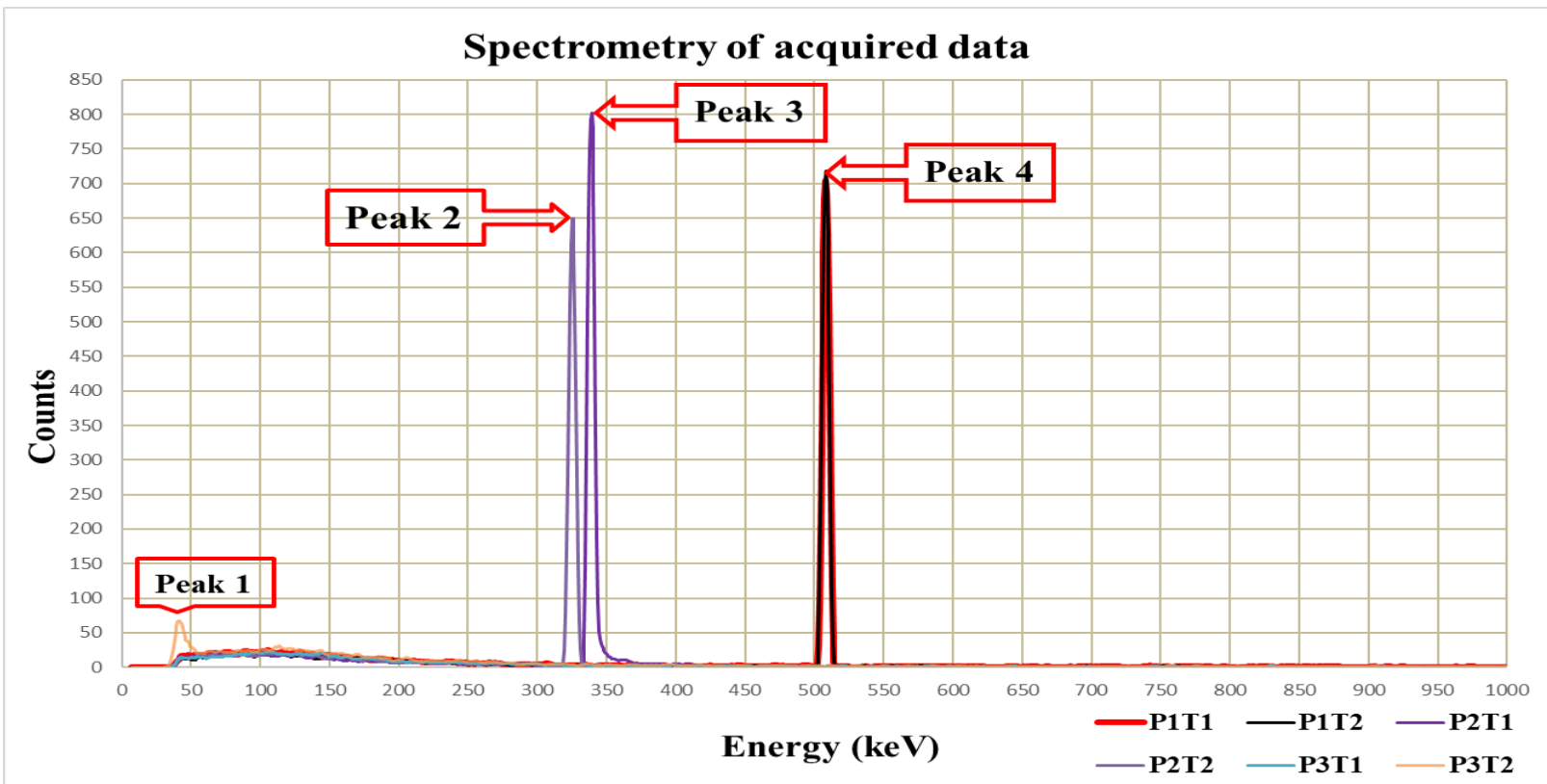

Figure 5 Shows the spectrum of the radioactivity measurements in the treatment room showing photopeak locations(P1T1 \& $\mathrm{P} 1 \mathrm{~T} 2$, trial $1 \& 2$ position 1; P2T1 \& P2T2, trial 1\& 2 position 2; P3T1 \& P3T2, trial 1\& 2 position 3). 
Dose vs. Energy Position 1

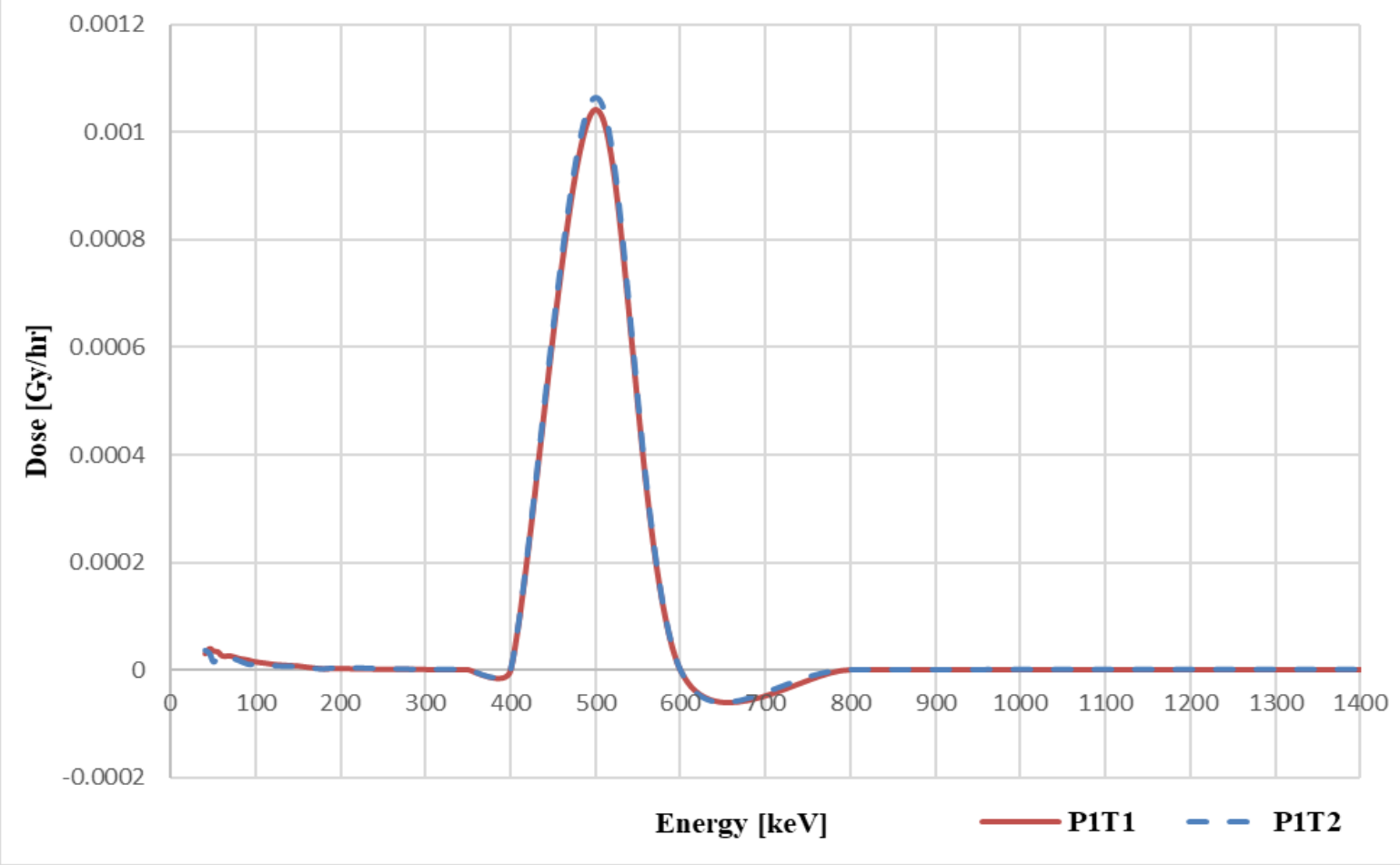

Figure 6 dose vs. energy graph at a distance of $25 \mathrm{~cm}$ from beam head

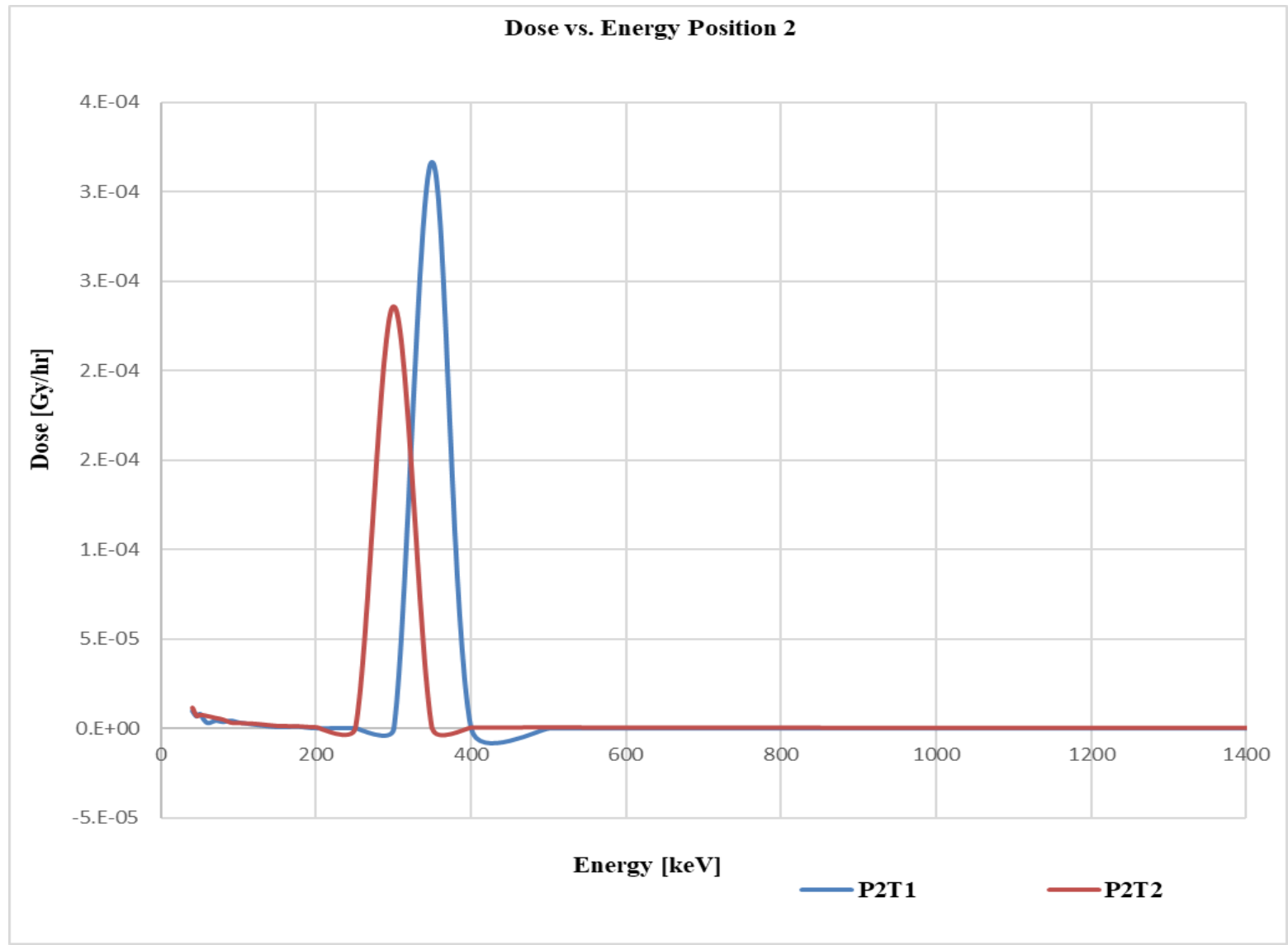

Figure 7 dose vs. energy graph at a distance of $50 \mathrm{~cm}$ from beam head 


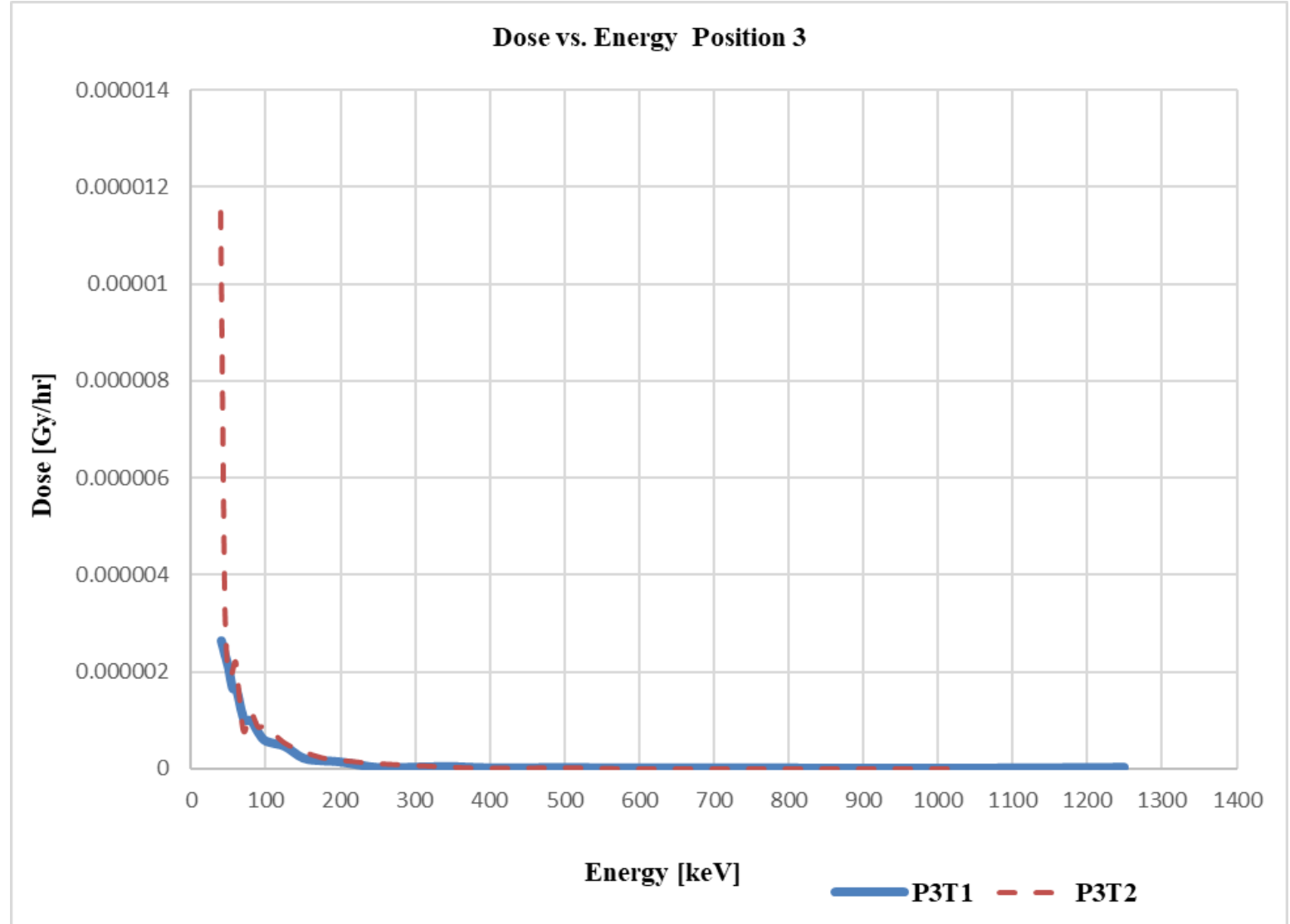

Figure 8 dose vs. energy graph at a distance of $100 \mathrm{~cm}$ from beam head 